\title{
Targeting PIM kinase enhances the activity of sunitinib in renal cell carcinoma
}

\section{Mahalingam', CM Espitia', EC Medina', JA Esquivel II', KR Kelly', D Bearss², G Choy², P Taverna², JS Carew', FJ Giles' and ST Nawrocki*,'}

'Department of Medicine, Institute for Drug Development, Cancer Therapy and Research Center, The University of Texas Health Science Center, 7979 Wurzbach Road, San Antonio, TX 78245, USA; ${ }^{2}$ SuperGen Inc., Dublin, CA 94568, USA

BACKGROUND: Upregulation of PIM kinase expression has been reported in many malignancies, suggesting that inhibition of PIM kinase activity may be an attractive therapeutic strategy. We hypothesised that inhibition of PIM kinase activity with SGI- I776, a novel small molecule inhibitor of PIM kinase activity, would reduce the viability of renal cell carcinoma (RCC) cells and enhance the activity of sunitinib.

METHODS: Immunoblotting, qRT-PCR, and gene expression arrays were carried out to identify genes modulated by SGI-I776 treatment. The anticancer activity of SGI-1776 and sunitinib was determined by viability and apoptosis assays and in tumour xenografts in vivo.

RESULTS: Treatment with SGI-I776 led to a decrease in phosphorylated and total c-Myc levels, which resulted in the modulation of c-Myc target genes. SGI-I776 in combination with sunitinib induced a further reduction in c-Myc levels, which was associated with enhanced anticancer activity. siRNA-mediated knockdown of c-Myc demonstrated that its expression has a key role in regulating the sensitivity to the combination of SGI-I776 and sunitinib. Importantly, the combination significantly reduced tumour burden in two RCC xenograft models compared with single-agent therapy and was very well tolerated.

CONCLUSION: These data indicate that targeting PIM kinase signalling is a promising treatment strategy for RCC.

British Journal of Cancer (2011) 105, 1563- 1573. doi:I0.1038/bjc.2011.426 www.bjcancer.com

Published online 20 October 2011

(C) 201 I Cancer Research UK

Keywords: PIM; SGI-I776; sunitinib; renal cell carcinoma; c-Myc

Renal cell carcinoma (RCC) accounts for $85 \%$ of kidney cancers with clear cell RCC (ccRCC) being the most common subtype representing $\sim 75 \%$ of all cases (Kaelin, 2008). Loss of expression of the von Hippel-Lindau (VHL) tumour suppressor causes stabilisation of hypoxia-inducible factors (HIFs) and occurs in $70 \%$ of sporadic ccRCC patients (Kaelin, 2007). Hypoxia-inducible factors alter the cellular environment by activating target genes involved in angiogenesis and metabolism (Turner et al, 2002). The anti-angiogenic multi-tyrosine kinase inhibitors sunitinib and sorafenib demonstrated efficacy for the treatment of RCC likely due to the highly vascularised nature of these tumours. Despite the success of these agents, drug resistance is a major obstacle that highlights the need for new treatment strategies to improve clinical outcomes (Sosman et al, 2007).

The PIM kinases are a family of serine/threonine kinases (PIM-1, PIM-2, PIM-3) that have been associated with tumourigenesis and drug resistance (Adam et al, 2006; Cibull et al, 2006; Beier et al, 2007; Chen et al, 2008, 2009a). All three kinases have an ATPbinding pocket, an active site, a kinase domain, and lack regulatory domains making them constitutively active. The expression of PIM kinases is mediated by the Janus-activated kinase/signal transducers and activators of transcription (STAT) signalling pathway

*Correspondence: Dr ST Nawrocki; E-mail: Nawrocki@uthscsa.edu Received II May 201I; revised I4 September 2011; accepted 21 September 201 I; published online 20 October 201 I
(Amaravadi and Thompson, 2005). PIM kinases regulate cell-cycle progression by directly phosphorylating p21, p27, Cdc25A, and Cdc25C and suppress apoptosis via phosphorylation of the pro-apoptotic protein Bad (Mochizuki et al, 1999; Li et al, 2006; Popivanova et al, 2007; Zhang et al, 2007b; Morishita et al, 2008; $\mathrm{Hu}$ et al, 2009). Overexpression of PIM-1 has been reported in haematological malignancies and in many solid tumours, which suggests that blocking PIM-1 kinase activity may be a promising approach for cancer therapy (Eichmann et al, 2000; Cibull et al, 2006; Beier et al, 2007; Chen et al, 2008; Hogan et al, 2008).

While PIM-1 is not a potent oncogene, it interacts synergistically with c-Myc to promote tumourigenesis (Moroy et al, 1991). Phosphorylation of c-Myc by PIM-1 leads to c-Myc stabilisation and enhanced transcriptional activity (Zippo et al, 2007; Zhang et al, 2008). Given the central role of Myc in many cancers, including RCC, inhibition of PIM-1 activity may promote Myc degradation and subsequently decrease tumour cell proliferation (Pelengaris et al, 2002; Nilsson and Cleveland, 2003; Tang et al, 2009). This approach may be especially effective in a subset of VHL-deficient RCCs that express HIF- $2 \alpha$, but not HIF- $1 \alpha$, which promotes elevated c-Myc activity (Gordan et al, 2007a, 2008).

In this study, we evaluated the efficacy of a novel small molecule inhibitor of PIM kinase activity, SGI-1776, in RCC alone and in combination with sunitinib. SGI-1776 demonstrated activity in a panel of RCC cell lines, which was associated with decreased phosphorylation of the PIM kinase substrates, Bad and c-Myc. 
Furthermore, SGI-1776 reduced total protein levels of c-Myc and microarray analyses displayed gene expression patterns consistent with blunted c-Myc activity. Importantly, targeting PIM-1 with either siRNA or SGI-1776 significantly enhanced the activity of sunitinib in RCC models. Our results establish that SGI-1776 decreases c-Myc levels, reduces RCC viability, and enhances the activity of sunitinib. Collectively, these findings indicate that inhibition of PIM kinase activity in combination with sunitinib warrants further investigation for the treatment of RCC and other malignancies.

\section{MATERIALS AND METHODS}

\section{Cells and cell culture}

786-O, A498, Caki-1, Caki-2, and ACHN renal cancer cell lines were obtained from the American Type Culture Collection (Manassas, VA, USA). Cancer cell lines were cultured in RPMI supplemented with $10 \%$ fetal bovine serum and maintained in a humidified incubator at $37{ }^{\circ} \mathrm{C}$ with $5 \% \mathrm{CO}_{2}$. Human normal renal proximal tubule epithelial cells (RPTECs) were purchased from Clonetics (Walkersville, MD, USA) and cultured in the recommended media (REGM BulletKit, Clonetics).

\section{Antibodies and reagents}

Antibodies were obtained from the following commercial sources: anti-PIM-1 (Santa Cruz Biotechnology, Santa Cruz, CA, USA); antiphospho-Bad (Ser112) and Bad (Cell Signaling, Danvers, MA, USA); anti-actin and tubulin (Sigma-Aldrich, St Louis, MO, USA); anti-c-Myc, phospho-c-Myc (Ser62), and Bad (immunohistochemistry) (Novus Biologicals, Littleton, CO, USA); antiproliferating cell nuclear antigen (PCNA) (Dako, Glostrup, Denmark); goat anti-rabbit horseradish peroxidase (HRP)-conjugated secondary antibodies (Jackson Laboratories, West Grove, PA, USA); Rat anti-mouse IgG2a-HRP (Serotec, Raleigh, NC, USA); and sheep anti-mouse-HRP and donkey anti-rabbit-HRP (Amersham, Pittsburgh, PA, USA). SGI-1776 was kindly provided by SuperGen Inc. (Dublin, CA, USA). Sunitinib was purchased from the Cancer Therapy and Research Center pharmacy.

\section{Quantification of drug-induced cytotoxicity}

Cell viability was assessed by 3-(4,5-dimethylthiazol-2-yl)-2,5diphenyltetrazolium bromide (MTT) assay and the pro-apoptotic effects of SGI-1776 and sunitinib were quantified by propidium iodide (PI) staining and fluorescence-activated cell sorting (FACS) analysis of sub- $\mathrm{G}_{0} / \mathrm{G}_{1}$ DNA content as previously described (Carew et al, 2009).

\section{Clonogenic survival assays}

Clonogenic survival assays were conducted as previously described (Mahalingam et al, 2010). Briefly, cells were treated with $5 \mu \mathrm{M}$ SGI$1776,5 \mu \mathrm{M}$ sunitinib, or the combination for $24 \mathrm{~h}$. After drug exposure, cells were washed twice in PBS followed by the addition of fresh media and incubated for 10 days in a humidified incubator at $37^{\circ} \mathrm{C}$ with $5 \% \mathrm{CO}_{2}$. Colonies were then washed in PBS, fixed with methanol, and stained with crystal violet. Colonies were scored using an Alpha Innotech (San Leandro, CA, USA) gel documentation system.

\section{Immunoblotting}

Renal cell carcinoma cells were treated with the indicated concentrations of drugs. Immunoblotting was performed as previously described (Nawrocki et al, 2008). Quantification of bands was performed using ImageJ software (Bethesda, MD, USA).

\section{Transfection of siRNAs}

PIM-1, c-Myc, and non-target SMARTpool siRNA were obtained from Dharmacon (Lafayette, CO, USA). Cells were transfected with $100 \mathrm{~nm}$ of each siRNA using Oligofectamine (Invitrogen, Carlsbad, CA, USA) according to the manufacturer's protocol. Transfected cells were incubated at $37^{\circ} \mathrm{C}$ for $24 \mathrm{~h}$ and then treated with SGI-1776, sunitinib, or the combination for $48 \mathrm{~h}$. Efficiency of RNAi was measured at $48 \mathrm{~h}$ by immunoblotting.

\section{Expression microarrays}

786-O and Caki-1 cells were treated with $5 \mu \mathrm{m}$ SGI-1776 for $24 \mathrm{~h}$. Following drug treatment, total RNAs were isolated using the RNeasy Plus Mini Kit (Qiagen, Germantown, MD, USA) and treated with TURBO DNA-free Kit (Applied Biosystems, Foster City, CA, USA). In all, $300 \mathrm{ng}$ of total RNA per sample was amplified and hybridised to GeneChip Human Gene 1.0 ST arrays (Affymetrix, Inc., Santa Clara, CA, USA) according to the manufacturer's instructions. Affymetrix CEL files were imported into Partek Genomics Suite 6.4 (Partek Inc., St Louis, MO, USA) using the default Partek normalisation parameters and the robust multi-array average (RMA) analysis adjusted for probe sequence and GC content (GC-RMA). Data normalisation was performed across all arrays using quantile normalisation.

\section{Quantitative real-time polymerase chain reaction}

786-O and Caki-1 cells were treated with $5 \mu \mathrm{M}$ SGI-1776 for $24 \mathrm{~h}$. cDNA from control and SGI-1776-treated cells were used for relative quantification by real-time polymerase chain reaction (RT-PCR) analyses. First-strand cDNA synthesis was performed from $1 \mu \mathrm{g}$ RNA in a 20 - $\mu$ l reaction mixture using the high-capacity cDNA Reverse Transcription Kit (Applied Biosystems). CDC25A, ODC1, SKP2, CDKN1A, DDIT3, PIM-1, and GAPDH transcripts were amplified using commercially available TaqMan Gene expression assays (Applied Biosystems). Relative gene expression was calculated with the $2^{-\triangle \Delta C t}$ method using GAPDH as a housekeeping gene (Pfaffl, 2001).

\section{Xenograft studies}

All experiments were conducted in accordance with the guidelines for the welfare and use of animals in cancer research (Workman et al, 2010). Animal protocols were approved by the Institutional Animal Care and Use Committee of the University of Texas Health Science Center at San Antonio. 786-O and Caki-1 renal cancer cells $\left(1 \times 10^{7}\right)$ were suspended in a mixture of HBSS and Matrigel (BD BioSciences, San Jose, CA, USA) and subcutaneously implanted into female nude mice (BALB/c background) from Harlan (Indianapolis, IN, USA). Tumour-bearing animals from each cell line xenograft were randomised into treatment groups. Mice were treated with vehicle, sunitinib $\left(40 \mathrm{mg} \mathrm{kg}^{-1}\right.$ PO), SGI-1776 $\left(200 \mathrm{mg} \mathrm{kg}^{-1}\right.$ free base PO), or both agents on a QDx5 (every day for 5 days) schedule for 3 weeks. Mice were monitored daily and tumour volumes were measured twice weekly.

\section{Immunohistochemistry}

Paraffin-embedded tumour sections were deparaffinised in xylene, treated with a graded series of alcohol, and rehydrated in PBS $(\mathrm{pH}$ 7.5). Heat-induced epitope retrieval was performed by microwaving slides in a citrate buffer. Primary antibodies were added and slides were incubated at $4{ }^{\circ} \mathrm{C}$ overnight. After washing with PBS, slides were incubated in appropriate secondary antibodies for $1 \mathrm{~h}$ at ambient temperature. Positive reactions were visualised by immersing the slides with stable 3,3-diaminobenzidi (Research Genetics, Huntsville, AL, USA) and counterstained with Gill's 
haematoxylin (Sigma). Images were captured using an Olympus fluorescent microscope (Center Valley, PA, USA) with a DP71 camera and a $\times 20$ objective. Image-Pro Plus software Version 6.2.1 (MediaCybernetics, Bethesda, MD, USA) was used for image acquisition and quantification by densitometric analysis of five random fields containing viable tumour cells.

\section{Terminal deoxyribonucleotide-transferase-mediated dUTP nick-end labelling assay}

DNA fragmentation was analysed using a FITC-labelled TUNEL assay kit (Promega, Madison, WI, USA). The assay was performed according to the manufacturer's instructions and PI was used to counterstain the nucleus. Percentages of TUNEL-positive cells were determined by manual counting of five random fields per section.

\section{Statistical analyses}

Statistical significance was determined using the Tukey-Kramer comparison test or the Student's $t$-test. Differences were considered significant in all experiments at $P<0.05$.

\section{RESULTS}

\section{PIM-1 expression is increased in RCC cells}

Upregulation of PIM kinase expression has been observed in many malignancies, but has not been investigated in RCC. Considering the proposed role of PIM-1 in tumourigenesis and drug resistance, we evaluated its expression in a panel of RCC cell lines and in normal RPTECs. PIM-1 displayed varying degrees of expression in RCC cell lines, but was consistently increased in all lines compared with normal RPTECs (Figure 1A).

A
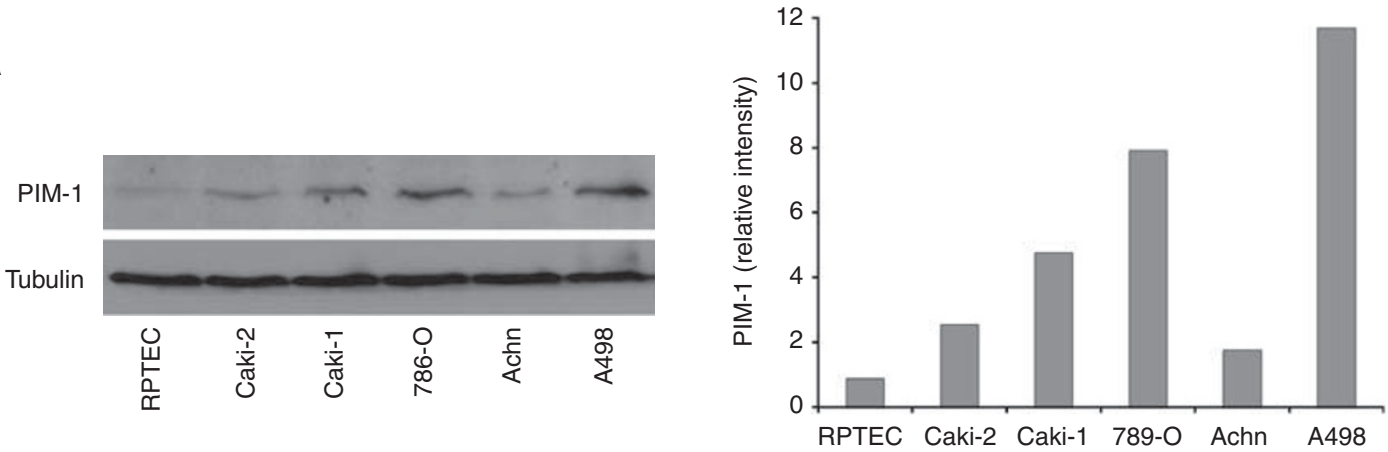

B
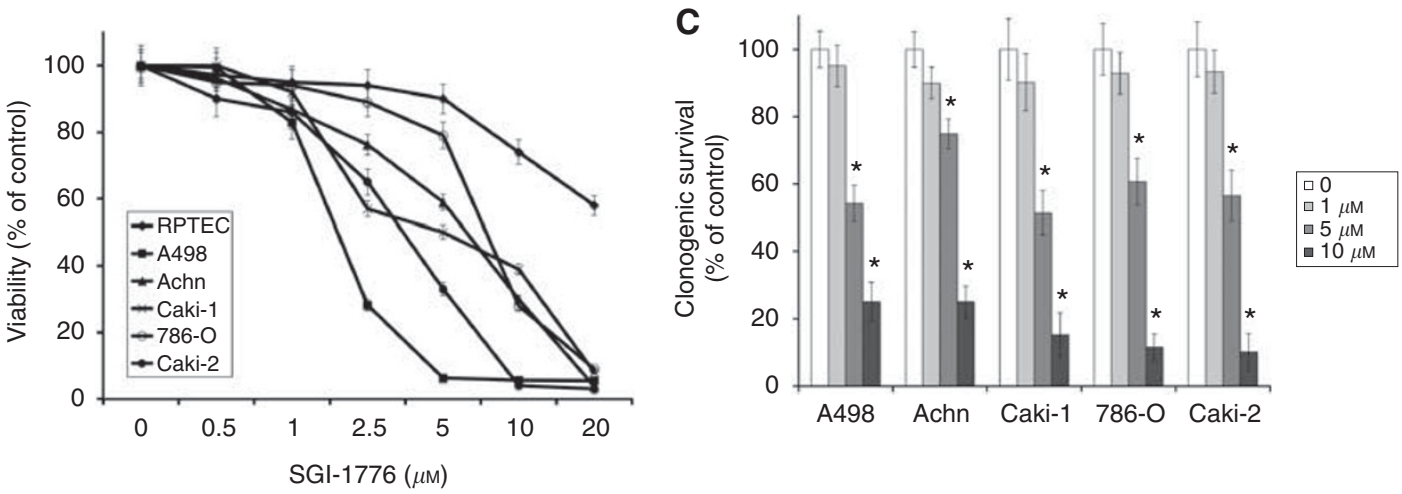

D
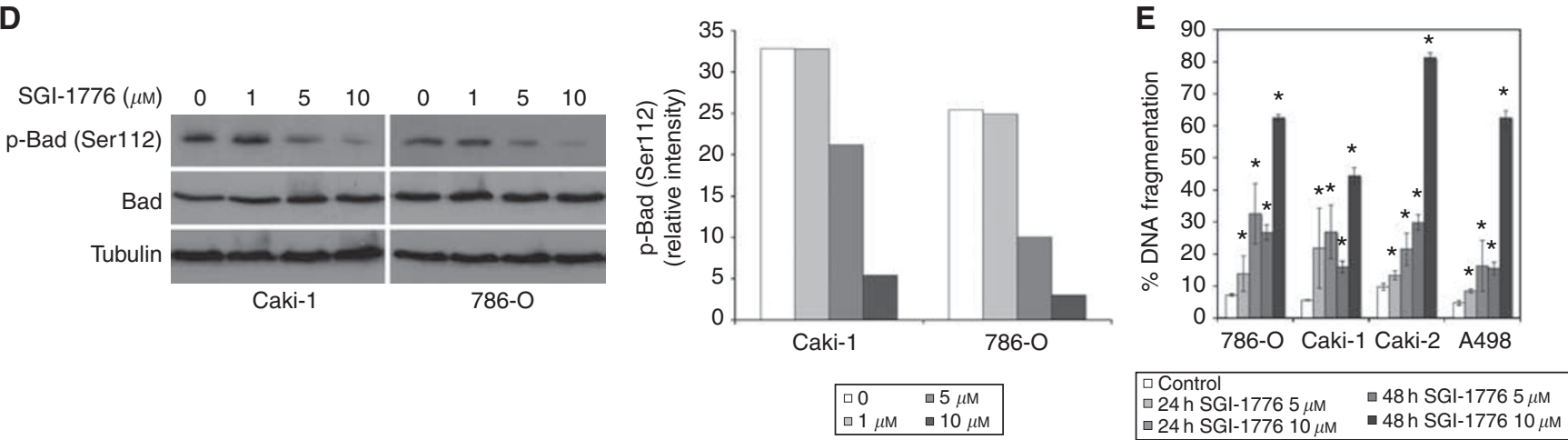

Figure I PIM-I is overexpressed in RCC cell lines and inhibition of PIM kinase activity with SGI- 1776 promotes apoptosis and reduced viability. (A) PIM- I kinase expression in RCC cell lines. Immunoblotting demonstrates elevated PIM-I levels compared with normal RPTECs. Band intensity was quantified using Image) software. (B) SGI- 1776 reduces RCC cell viability. Five RCC cell lines and RPTEC cells were incubated with the indicated concentrations of SGI- I776 for $72 \mathrm{~h}$ and cell viability was measured by MTT assay. Mean \pm s.d., $n=3$. (C) SGl- 7776 reduces RCC clonogenic survival. Cells were treated with indicated concentrations of SGl-1776 for $24 \mathrm{~h}$, washed and incubated in fresh media for 10 days. Colonies were fixed, stained with crystal violet and quantified. Mean \pm s.d., $n=3$. * Indicates a significant difference compared with control. $P<0.05$. (D) SGI- 1776 decreases Bad phosphorylation at Serl I 2. Cells were treated with SGI-1776 for $48 \mathrm{~h}$ and phospho- and total Bad levels were determined by immunoblotting. Phospho-Bad band intensity was quantified using Image) software. (E) SGI-I776 induces apoptosis in RCC cell lines. Cells were treated with SGI-I776 for $48 \mathrm{~h}$ and apoptosis was measured by PI-FACS analysis. Mean \pm s.d., $n=3$. *Indicates a significant difference compared with control. $P<0.05$. 
A

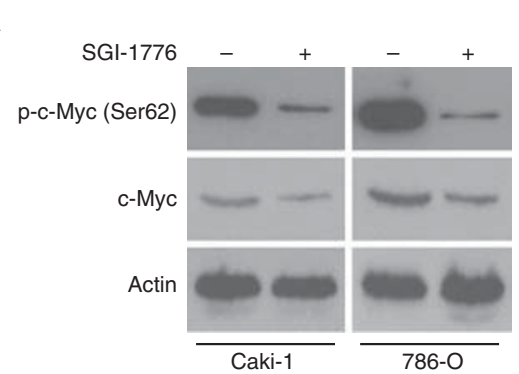

B

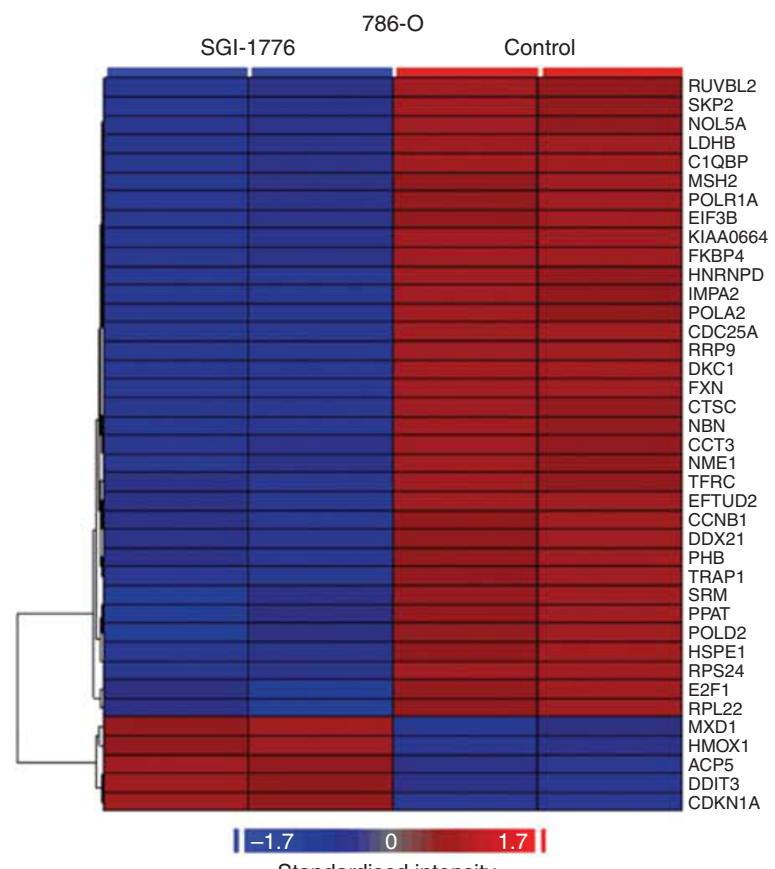

C

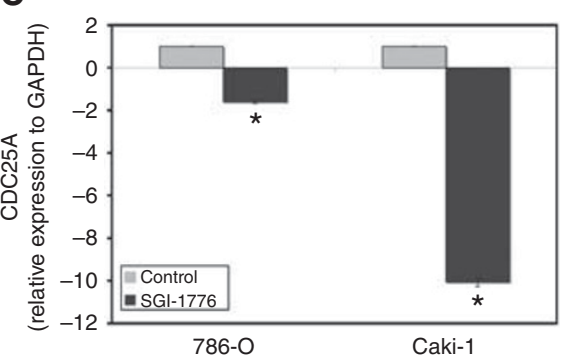

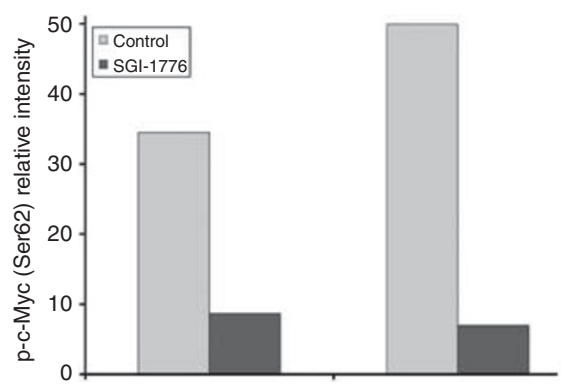

$786-0$

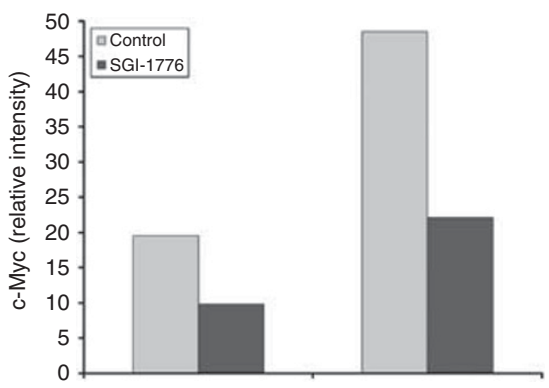

Caki-1

$786-\mathrm{O}$

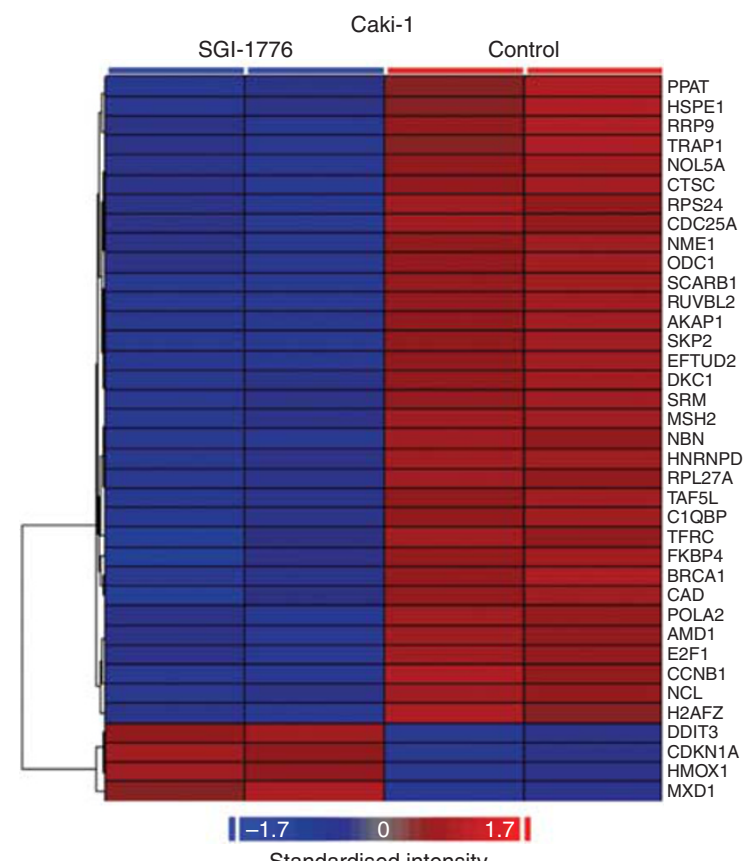

Standardised intensity
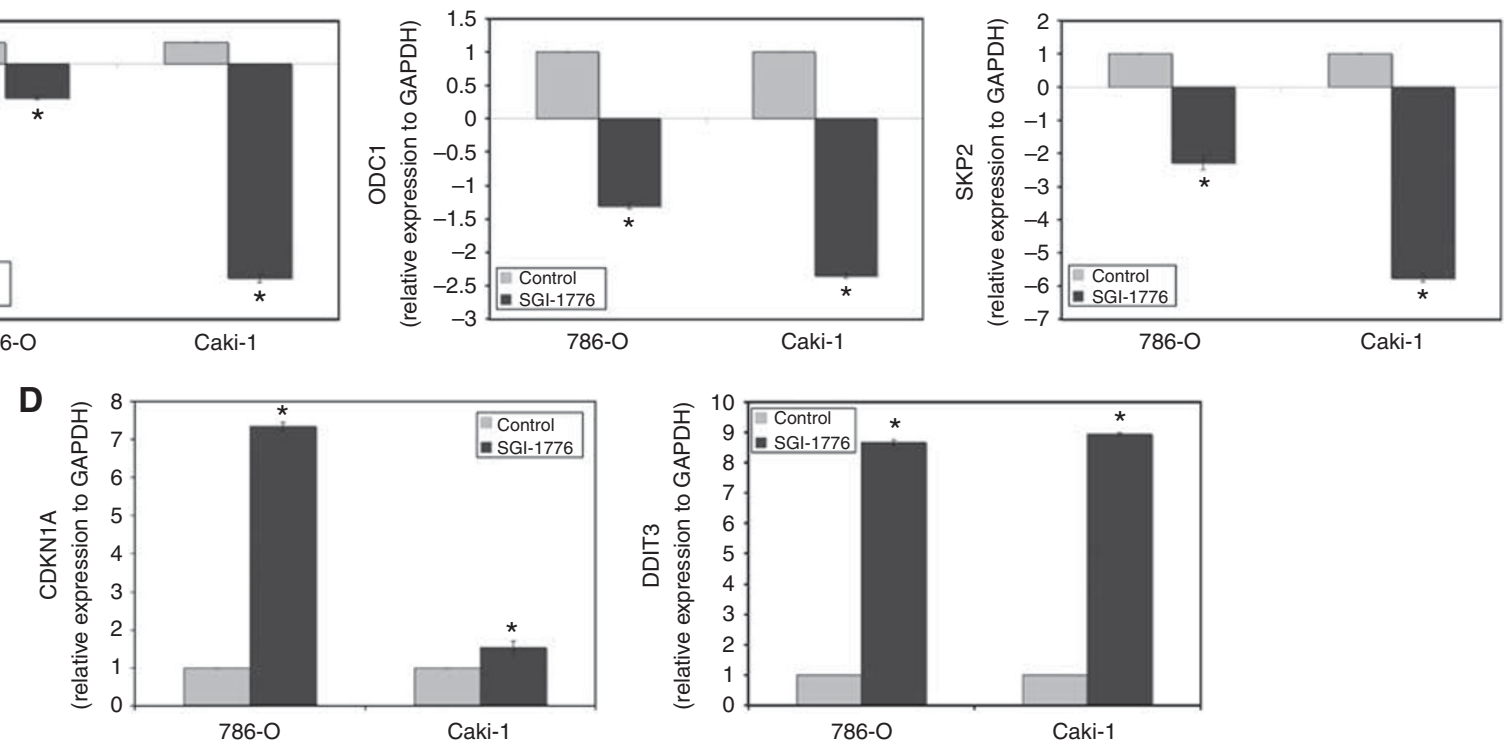

Figure 2 SGI-I776 decreases phospho- and total c-Myc levels, resulting in altered expression of c-Myc target genes. (A) SGI- I776 reduces functional c-Myc levels. RCC cells were treated with $5 \mu \mathrm{M} \mathrm{SGl-1} 776$ for $48 \mathrm{~h}$. Phospho- and total c-Myc levels were measured by immunoblotting. Phospho-c-Myc and c-Myc band intensity was quantified using Imagel software. (B) Affymetrix expression arrays identify differential expression of c-Myc target genes following $24 \mathrm{~h}$ treatment with $5 \mu \mathrm{M} \mathrm{SGl-1776.} \mathrm{Blue} \mathrm{corresponds} \mathrm{to} \mathrm{reduced} \mathrm{gene} \mathrm{expression} \mathrm{and} \mathrm{red} \mathrm{corresponds} \mathrm{to} \mathrm{increased} \mathrm{expression.} \mathrm{RNA} \mathrm{isolation} \mathrm{and}$ expression arrays were performed as described in Materials and methods. (C and $\mathbf{D})$ qRT-PCR analysis of selected genes that are upregulated (CDC25A,

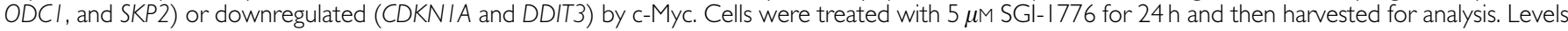
of mRNAs were standardised to the expression of GAPDH. Mean \pm s.d., $n=3$. *Indicates a significant difference from the controls. $P<0.05$. 
A

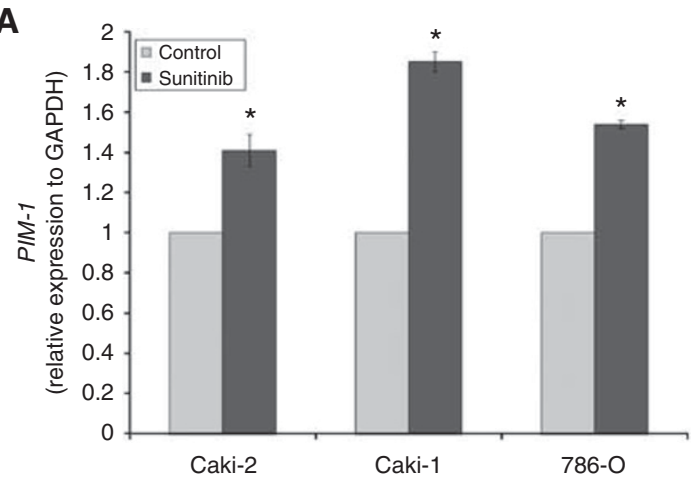

C

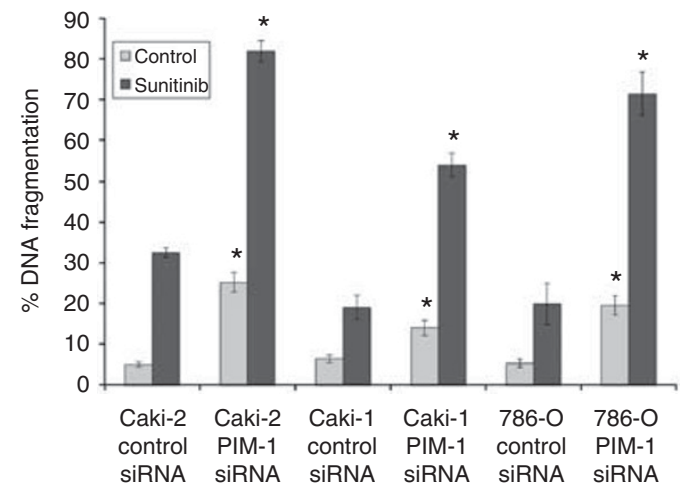

B
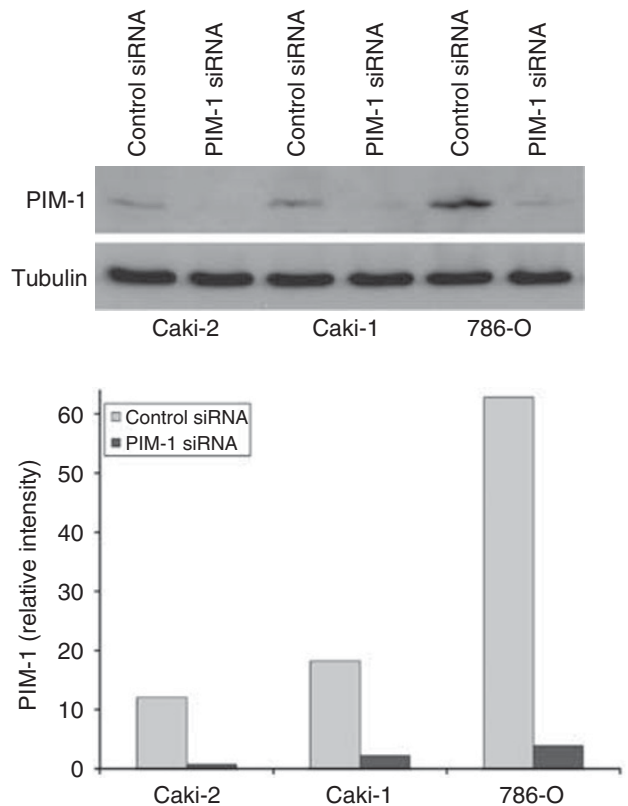

D
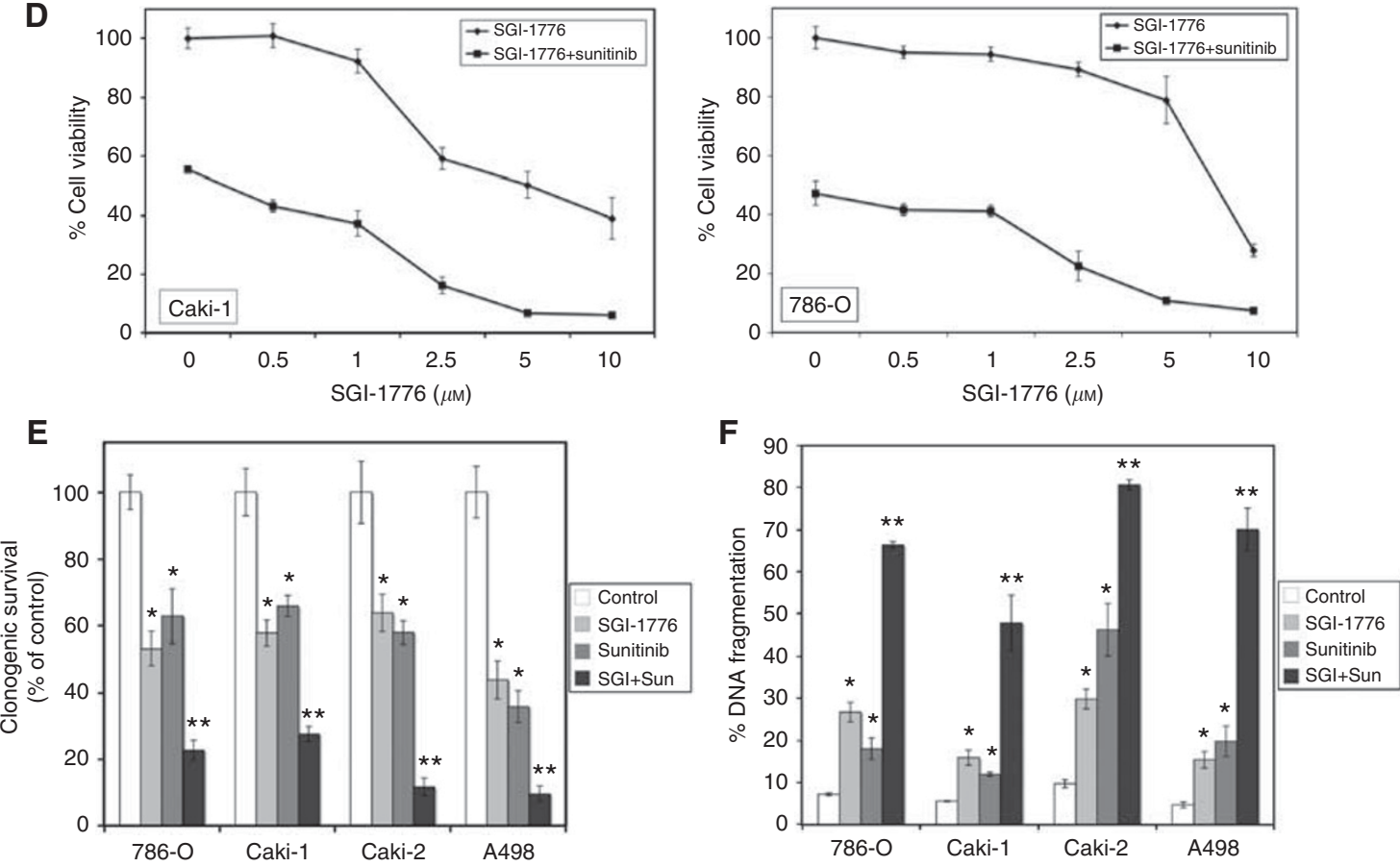

Figure 3 Inhibition of PIM-I kinase activity augments sunitinib-induced cell death. (A) Sunitinib induces PIM-I expression. Cells were treated for $24 \mathrm{~h}$ with $5 \mu \mathrm{M}$ sunitinib and PIM-I levels were measured by qRT-PCR. PIM-I expression was standardised to GAPDH. Mean \pm s.d., $n=3$. *Indicates a significant difference from the controls. $P<0.05$. (B) Silencing PIM-I expression using siRNA. Cells were transfected with control or PIM-I siRNA and PIM-I expression levels were determined by immunoblotting. Band intensity was quantified using Image) software. (C) Knockdown of PIM-I sensitises RCC cells to sunitinib-induced apoptosis. Cells were transfected with control or PIM-I siRNA. After transfection, cells were treated with $5 \mu$ M sunitinib for 48 h. Apoptosis was measured by PI-FACS analysis. Mean \pm s.d., $n=3$. *Represents a significant difference compared with control siRNA-transfected cells. (D) SGI- 7776 in combination with sunitinib reduces RCC cell viability. Cells were incubated with increasing concentrations of SGI- I776 with $5 \mu \mathrm{M}$ sunitinib for $72 \mathrm{~h}$ and cell viability was measured by MTT assay. Mean \pm s.d., $n=3$. Note: Single-agent sunitinib treatment is represented by the $0-\mu \mathrm{M}$ SGI- 1776 concentration of the SGI- 1776 + sunitinib group. (E) SGI- 1776 augments the effects of sunitinib on clonogenic survival. RCC cells were treated with $5 \mu \mathrm{M}$ SGI-I776, $5 \mu \mathrm{M}$ sunitinib, or both agents for $24 \mathrm{~h}$. Cells were washed and incubated in fresh media for 10 days. Colonies were then fixed, stained with crystal violet, and quantified. Mean \pm s.d., $n=3$. (F) SGI-I776 enhances sunitinib-induced apoptosis. Apoptosis was determined by PI-FACS analysis. Mean \pm s.d., $n=3$. *Indicates a significant difference compared with controls and **indicates a significant difference compared with either single-agent treatment. $P<0.05$. 

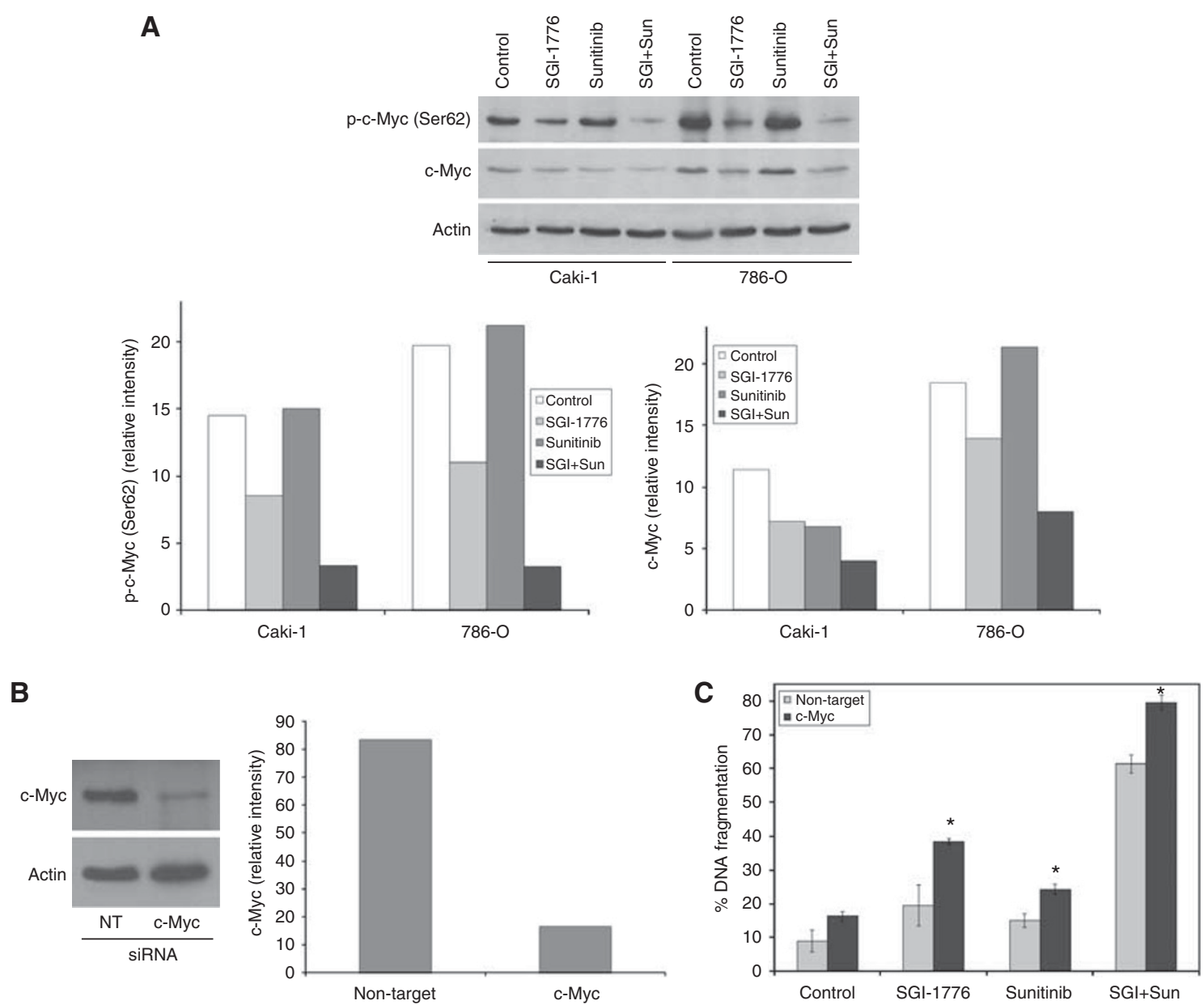

Figure 4 Knockdown of c-Myc levels augments the activity of SGI-I776 and sunitinib. (A) The combination of SGI-I776 and sunitinib stimulates a further

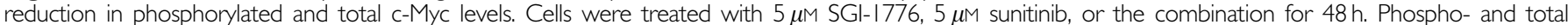
c-Myc levels were detected by immunoblotting. Phospho- and total c-Myc levels were quantified by densitometry using Image) software. (B) Silencing c-Myc expression using siRNA. Cells were transfected with non-target control or c-Myc siRNA and c-Myc expression levels were determined by immunoblotting at $48 \mathrm{~h}$. Band intensity was quantified using ImageJ software. (C) Knockdown of c-Myc enhances SGI- 7776 and sunitinib-mediated apoptosis. 786-O cells were transfected

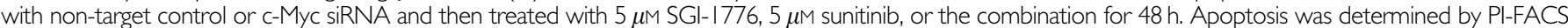
analysis. Mean \pm s.d., $n=3$. *Indicates a significant difference compared with the non-target transfected cells treated under the same conditions. $P<0.05$.

\section{The PIM kinase inhibitor SGI-1776 reduces RCC viability}

We next evaluated the ability of the small molecule PIM kinase inhibitor SGI-1776 to reduce RCC viability. The MTT assays demonstrated that SGI-1776 exhibited activity against all of the RCC lines tested with less toxicity against normal RPTEC cells (Figure 1B). Furthermore, SGI-1776 also effectively reduced RCC cell clonogenic survival (Figure 1C). PIM kinases have been previously reported to phosphorylate the pro-apoptotic protein Bad at Ser112, which promotes its sequestration in the cytosol by 14-3-3 and thus, blocks its mitochondrial interaction with Bcl-2 or Bcl-X (Fox et al, 2003; Yan et al, 2003; Aho et al, 2004; Li et al, 2006). Therefore, we hypothesised that inhibition of PIM kinase activity may stimulate apoptosis by freeing Bad to interact with antiapoptotic proteins. As expected, abrogation of PIM kinase activity reduced Bad phosphorylation at Ser112 (Figure 1D) and induced apoptosis in a panel of RCC cell lines (Figure 1E).

\section{SGI-1776 inhibits c-Myc phosphorylation and modulates the expression of c-Myc target genes}

In addition to Bad, another target of PIM kinase phosphorylation is the oncogene c-Myc. Overexpression of PIM kinases are frequently associated with elevated Myc levels. Since c-Myc has an important role in the biology of RCC, we determined the effect of SGI-1776 on its phosphorylation status in the $786-\mathrm{O}$ and Caki-1 cell lines. Treatment with SGI-1776 induced a strong reduction in c-Myc phosphorylation at Ser62 (Figure 2A). In accordance with the reports that this phosphorylation site promotes protein stability, SGI-1776 exposure also resulted in a decrease in total c-Myc protein expression (Figure 2A). Expression profiling (Figure 2B) and qRT - PCR (Figures $2 \mathrm{C}$ and D) analyses of RNA isolated from SGI-1776-treated 786-O and Caki-1 cells showed significant changes in the levels of c-Myc target genes that were consistent with reduced c-Myc activity. c-Myc behaves as both a transcriptional activator and repressor, inducing transcription of genes (e.g., CDC25A, ODC, and SKP2) by binding to CACGTG regions in a complex with Max, and blocking the transcription of other genes (e.g., CDKN1A) while complexed with Max and Miz1 or Sp1 (Nilsson and Cleveland, 2003; Gordan et al, 2007b). Collectively, our results suggest that inhibition of PIM kinase activity with SGI-1776 decreases functional c-Myc protein levels and corresponding transcriptional activity.

\section{Inhibition of PIM-1 activity enhances the activity of sunitinib in RCC}

The multi-tyrosine kinase inhibitor sunitinib is given as first-line therapy for the treatment of metastatic RCC. Although sunitinib 


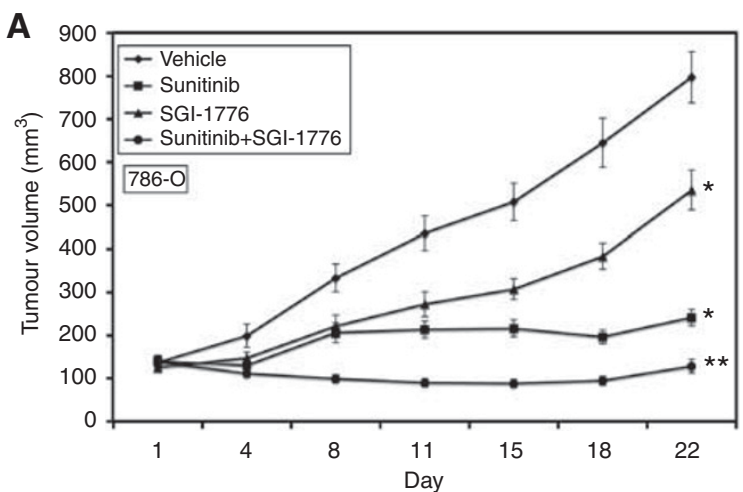

C
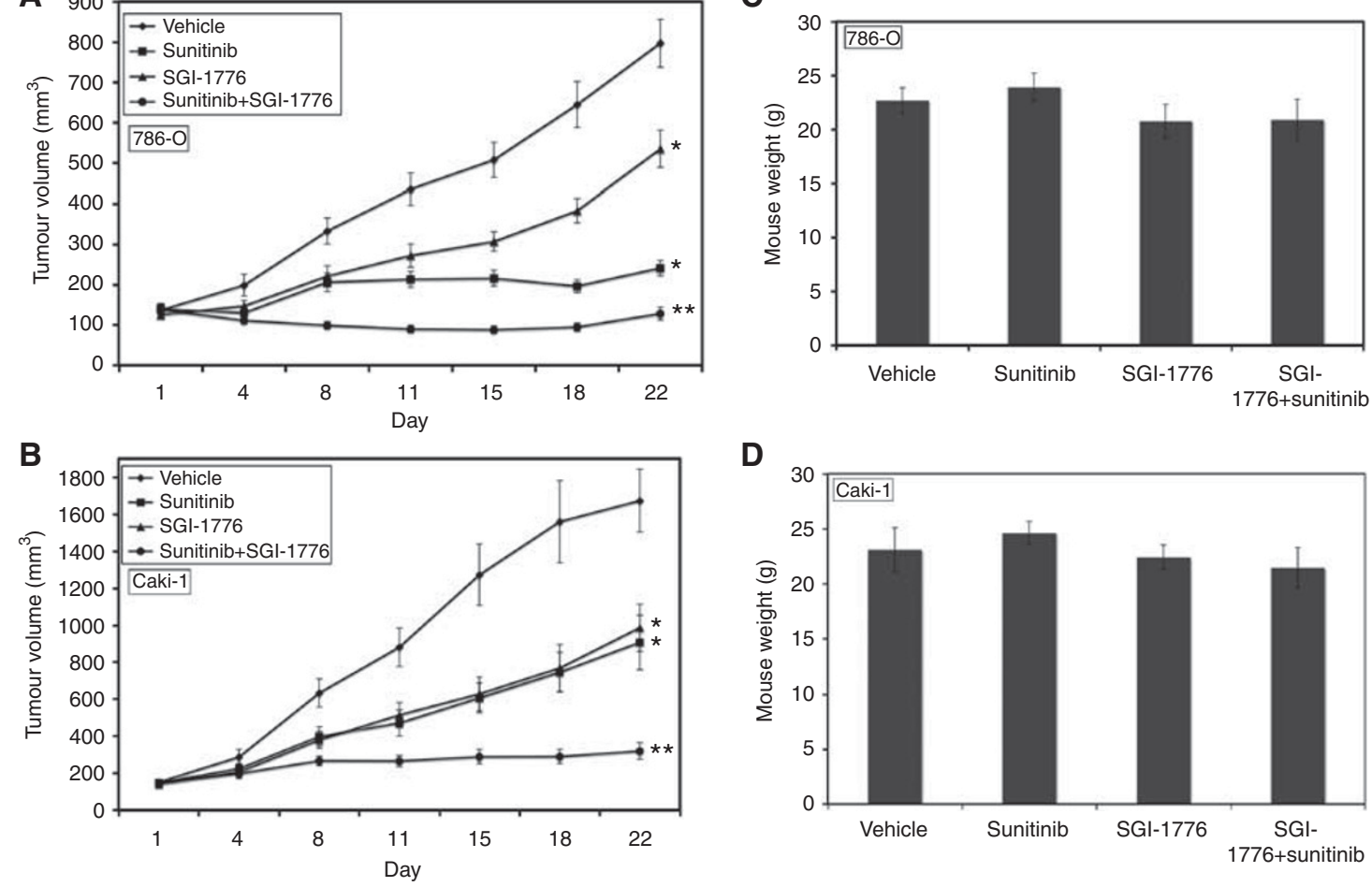

D

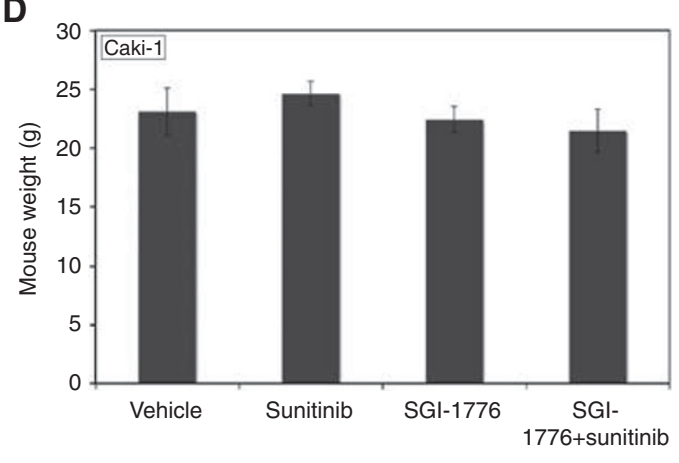

Figure 5 SGl-I776 enhances the activity of sunitinib in RCC xenograft models. (A and B) $786-O$ and Caki-I cells $\left(I \times 10^{7} / \mathrm{mouse}\right)$ were injected into the flanks of nude mice. When tumours reached $\sim 150 \mathrm{~mm}^{3}$ in size, mice were randomised into groups and treated on a QD×5 schedule with $200 \mathrm{mg} \mathrm{kg}^{-}$ SGl- I776, $40 \mathrm{mg} \mathrm{kg}^{-1}$, or both agents for 3 weeks. Tumours were measured twice weekly. Mean \pm s.e.m., $n=9$. *Indicates a significant difference compared with vehicle and **represents a significant difference compared with either single-agent treatment. $P<0.05$. (C and D) SGI-I776 and sunitinib are well tolerated in vivo. Xenograft studies were carried out as described in Materials and methods. Animal body weight was determined at the end of the study (day 22) to quantify drug-induced weight loss. Mean \pm s.d., $n=9$.

has demonstrated clinical benefit in RCC, drug resistance continues to be a major obstacle (Heng and Bukowski, 2008). Sunitinib treatment stimulated a significant increase in PIM-1 expression levels, suggesting that PIM-1 activity may promote resistance to sunitinib-induced apoptosis (Figure $3 \mathrm{~A}$ ). In order to further investigate this possibility, we utilised siRNA to knockdown PIM-1 levels (Figure 3B). This demonstrated that targeted PIM-1 knockdown significantly sensitised RCC cells to sunitinib (Figure 3C). Consistent with this result, addition of SGI-1776 to sunitinib markedly decreased cell viability in RCC cell lines (Figure 3D). We next evaluated the effects of SGI-1776 and sunitinib on clonogenic survival and apoptosis. Importantly, the combination significantly reduced clonogenic survival (Figure 3E) and induced apoptosis (Figure 3F) in a panel of RCC cell lines.

\section{Treatment with SGI-1776 and sunitinib reduces c-Myc levels}

To further evaluate the enhanced efficacy of PIM kinase inhibition in combination with sunitinib, we investigated the effects of this drug combination on c-Myc expression. Treatment with sunitinib alone did not significantly alter c-Myc phosphorylation. However, further reductions in $\mathrm{c}-\mathrm{Myc}$ phosphorylation and total $\mathrm{c}-\mathrm{Myc}$ levels were observed in combination-treated cells (Figure 4A). To determine whether drug-induced inhibition of c-Myc expression/ activity is a critical determinant of the therapeutic efficacy of these agents, c-Myc levels were silenced using siRNA (Figure 4B) and treated with both single agents and the combination (Figure 4C). The anticancer activity of SGI-1776, sunitinib, and the combination were all significantly enhanced by c-Myc silencing, which suggests that modulation of c-Myc expression is a critical event underlying the efficacy of this combination.

\section{SGI-1776 augments the activity of sunitinib to reduce tumour burden in RCC xenografts}

To further investigate the potential benefit of the SGI-1776 and sunitinib combination, their activity was evaluated in two RCC xenograft models. 786-O and Caki-1 tumour-bearing animals were randomised into treatment groups and given $200 \mathrm{mg} \mathrm{kg}^{-1}$ SGI-1776, $40 \mathrm{mg} \mathrm{kg}^{-1}$ sunitinib, or the combination for 3 weeks on a QDx5 (every day for 5 days) schedule. Treatment with SGI-1776 or sunitinib alone resulted in a significant decrease in mean tumour volume in both xenograft models compared with the vehicle-treated controls (Figures $5 \mathrm{~A}$ and $\mathrm{B}$ ). Sunitinib elicited a more potent response in $786-\mathrm{O}$ tumours compared with Caki-1, which may be due to the absence of VHL expression in 786-O. SGI-1776 dramatically enhanced the efficacy of sunitinib in both RCC models regardless of VHL status (Figures 5A and B). Importantly, all drug treatments were very well tolerated as no significant animal weight loss was observed at study completion (Figures 5C and D).

\section{SGI-1776 reduces Bad phosphorylation (Ser112) and induces apoptosis in RCC xenograft models}

Since the phosphorylation of the pro-apoptotic protein $\mathrm{Bad}$ at Ser112 is a common marker of PIM kinase inhibition, its expression was evaluated in both tumours by immunohistochemistry. As expected, SGI-1776 induced a reduction in Bad phosphorylation without altering total Bad protein levels 
A
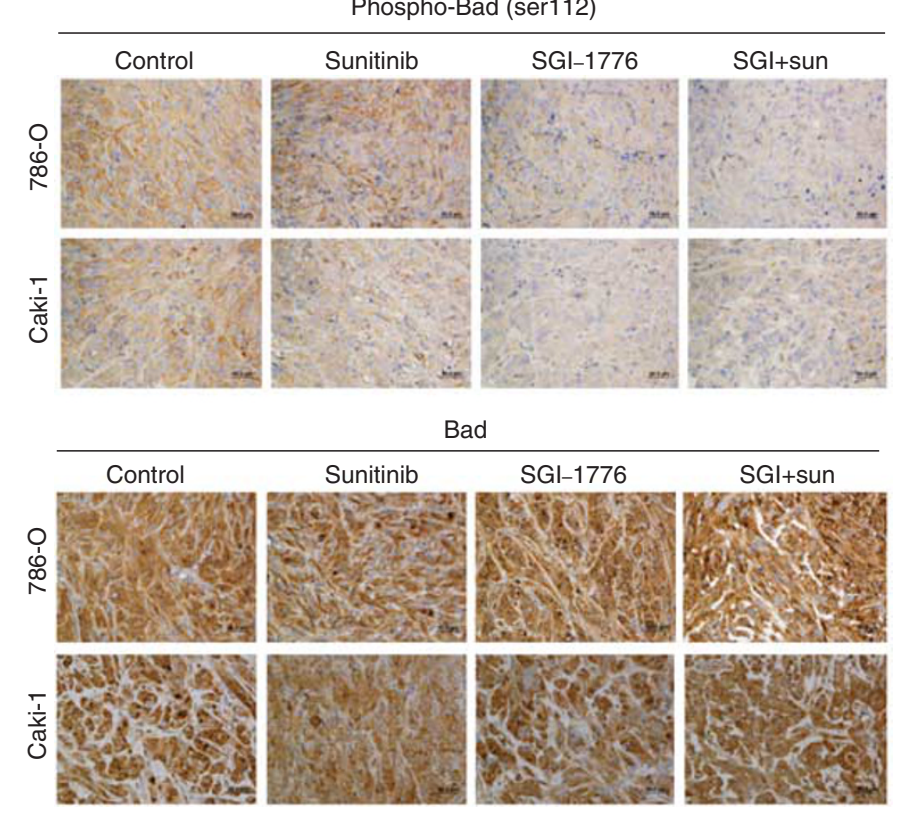

SGI+sun
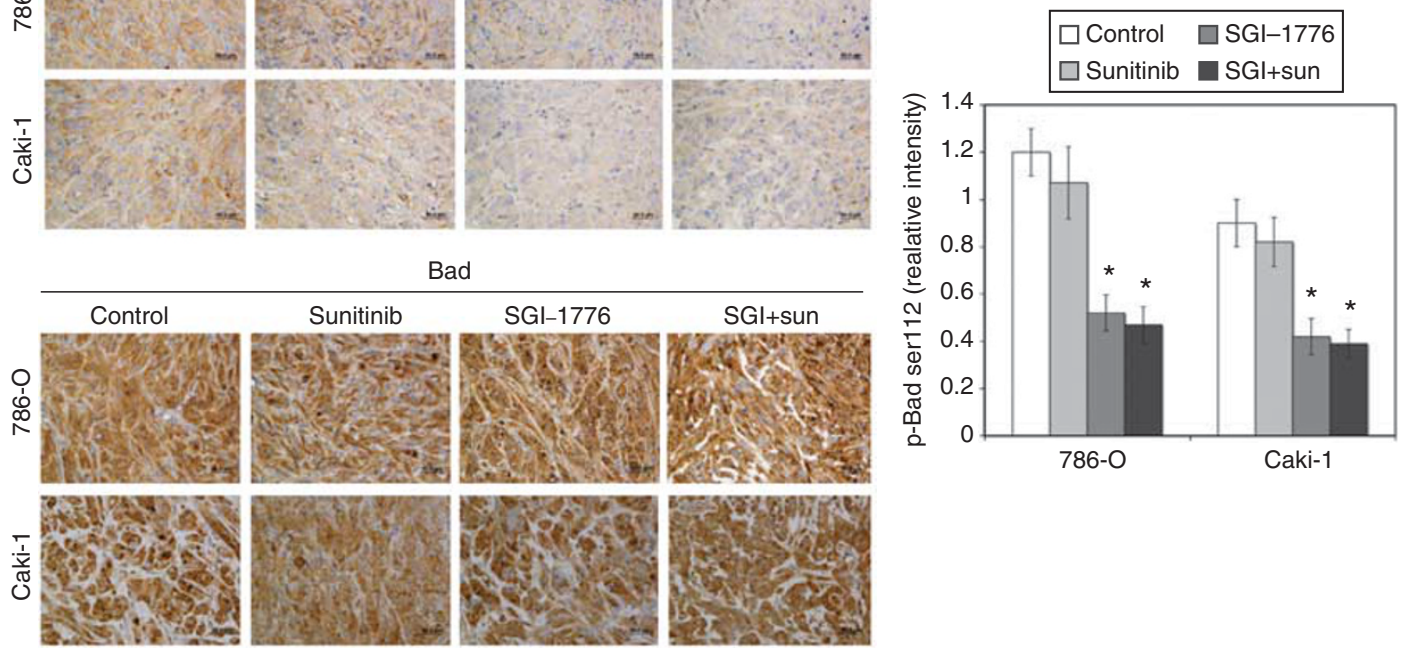

B
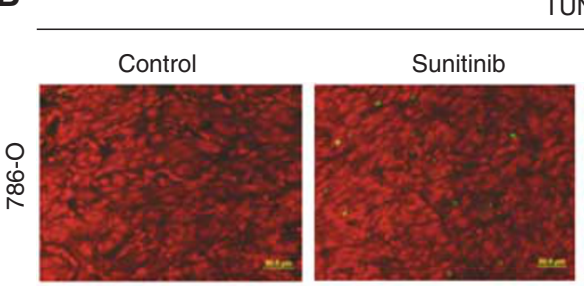

TUNEL
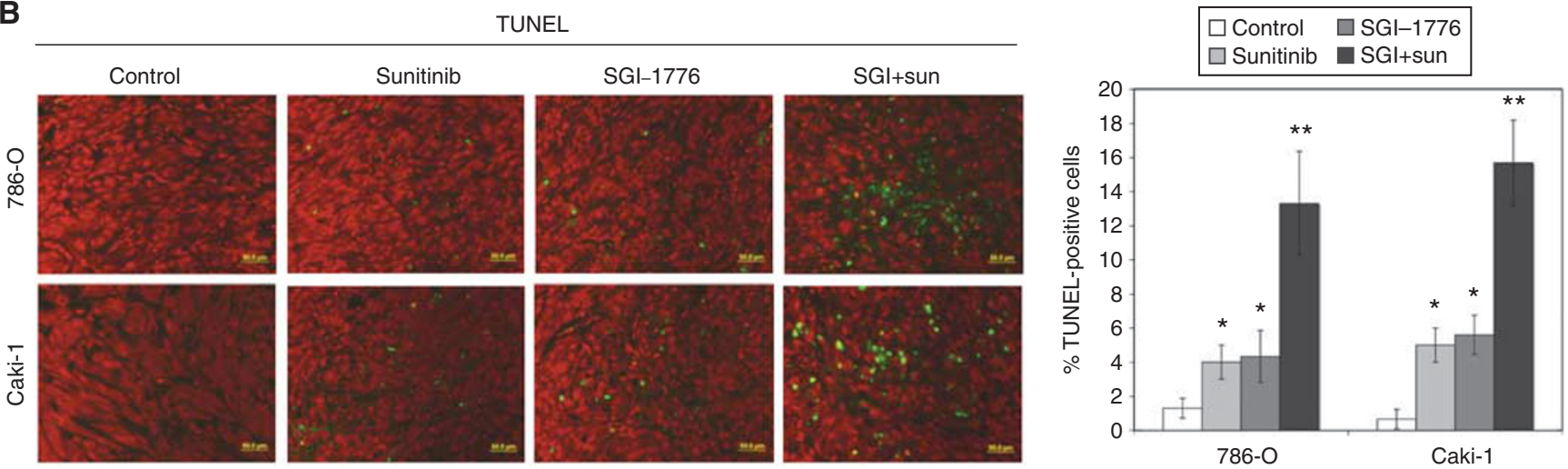

Figure 6 SGI-1776 reduces Bad phosphorylation and induces apoptosis in RCC tumours. (A) Phospho- and total Bad immunohistochemistry. Tumours were stained with either an antibody to phospho (Ser I2) or total Bad and analysed by immunohistochemistry. The relative intensity of phospho-Bad expression was measured using Image-Pro Plus software Version 6.2.I. Mean \pm s.d., $n=5$. * Indicates a significant difference compared with controls. $P<0.05$ No significant differences were observed in total Bad expression in the different treatment groups. (B) SGl- 1776 and sunitinib induce apoptosis. Apoptosis was measured by TUNEL staining as described in Materials and methods. Quantification was conducted by manually counting TUNEL-positive cells. Mean \pm s.d., $n=5$. *Indicates a significant difference compared with controls and **represents a significant difference compared with single-agent treatments. $P<0.05$.

(Figure 6A). The addition of sunitinib did not alter the ability of SGI-1776 to decrease Bad phosphorylation. While SGI-1776 induced moderate levels of apoptosis, it significantly augmented sunitinib-mediated apoptosis in both xenograft models (Figure 6B). These data suggest that apoptosis induction adds to the anticancer efficacy of the SGI-1776 and sunitinib combination.

\section{Suppression of c-Myc levels is associated with a decrease in tumour cell proliferation}

Our in vitro studies demonstrated that modulation of c-Myc levels contributes to the activity of the SGI-1776/sunitinib combination. Immunohistochemistry was performed on the tumours to evaluate the effects of the drugs on phosphorylated and total c-Myc levels and tumour proliferation (PCNA). Consistent with our in vitro data, SGI-1776 decreased phospho- (Ser62) and total c-Myc levels in both tumour models (Figures 7A and B). The addition of sunitinib to SGI-1776 resulted in a further reduction in c-Myc levels, which was associated with decreased tumour cell proliferation (Figure 7C). Collectively, our data establish an important role for c-Myc in controlling RCC proliferation, which can be therapeutically targeted via PIM kinase inhibition to enhance the efficacy of the standard of care agent sunitinib.

\section{DISCUSSION}

Increased PIM kinase expression has been reported in many tumour types and is associated with tumourigenesis and drug resistance (Adam et al, 2006; Cibull et al, 2006; Beier et al, 2007; Popivanova et al, 2007; Hogan et al, 2008; Chen et al, 2009a). Consistent with this observation, PIM-1 levels were also elevated in RCC cell lines compared with RPTECs. Therefore, PIM-1 kinase activity may be a promising target for RCC. PIM-1 kinase phosphorylates the oncogene c-Myc, which strongly increases its stability (Zhang et al, 2008). c-Myc modulates the expression of a broad range of genes involved in cell-cycle progression, proliferation, metabolism, apoptosis, and angiogenesis (Pelengaris et al, 2002; Nilsson and Cleveland, 2003). While c-Myc overexpression occurs in a large percentage of tumours, it may have an especially 
A

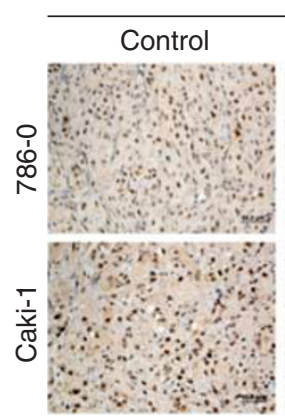

Phospho-c-Myc

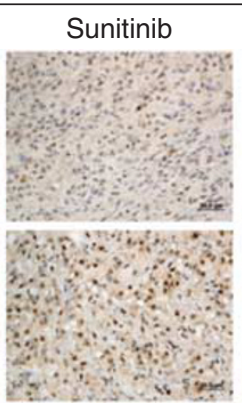

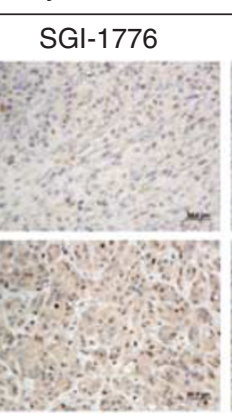

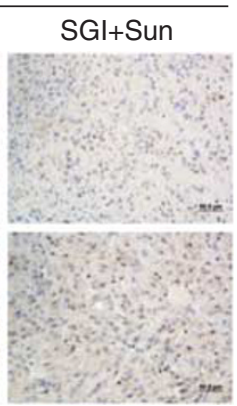

B

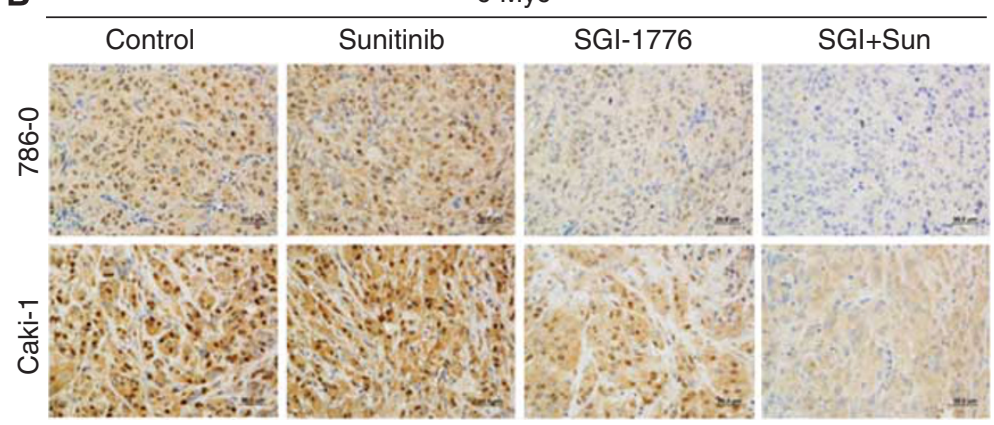

C

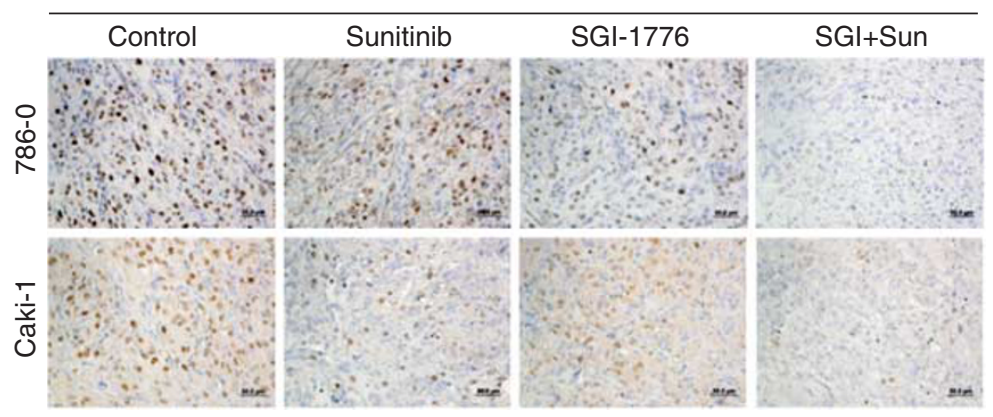

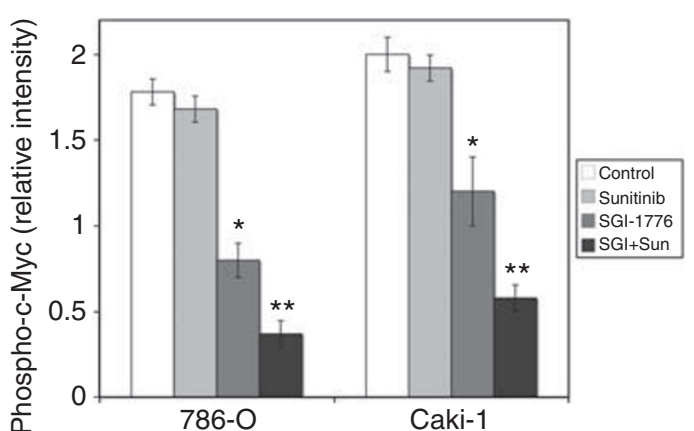
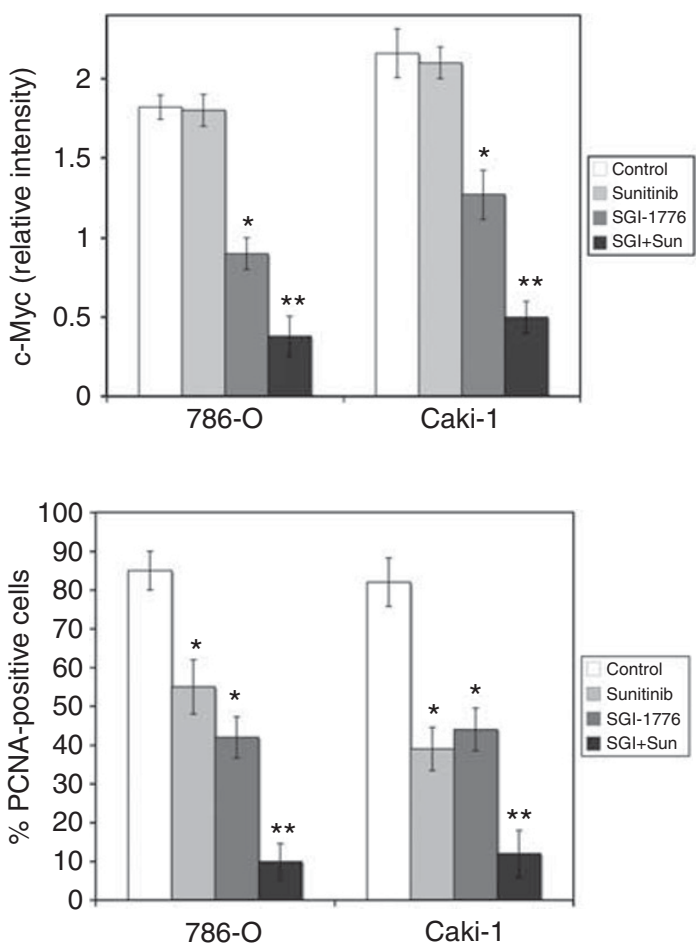

Figure 7 The combination of SGI-I 776 and sunitinib significantly reduces c-Myc levels and decreases tumour cell proliferation. (A and B) The SGI- I776/ sunitinib combination decreases c-Myc expression. Phospho- and total c-Myc levels were detected by immunohistochemistry. The relative intensities of phospho- and total c-Myc levels were measured using Image-Pro Plus software Version 6.2.I. Mean \pm s.d., $n=5$. *Indicates a significant difference compared with controls and **indicates a significant difference compared with single-agent treatments. $P<0.05$. (C) SGI-I776 and sunitinib reduce tumour cell proliferation. Tumour sections were stained with PCNA antibody. Positive cells were scored manually. Mean \pm s.d., $n=5$. *Indicates a significant difference compared with controls and **represents a significant difference compared with single-agent treatments. $P<0.05$.

important role in RCC due to the intrinsic hypoxic microenvironment that is characteristic of this tumour type (Tang et al, 2009). Furthermore, hypoxia has been reported to induce PIM-1 expression (Chen et al, 2009a). Consistent with c-Myc being a target for PIM-1, SGI-1776 treatment resulted in a reduction in c-Myc phosphorylation and total c-Myc protein levels. Thus, inhibition of PIM-1 kinase activity may be a novel approach to disrupt c-Myc function by promoting its degradation.

HIF $\alpha$ subunits are continuously being transcribed, but are targeted for proteasomal degradation under normoxic conditions by the VHL E3 ubiquitin ligase (Iliopoulos et al, 1996; Ohh et al, 2000). von Hippel-Lindau-defective tumours have high levels of HIF $\alpha$ and can be subdivided into two groups, tumours with both HIF- $1 \alpha$ and HIF- $2 \alpha$ (H1H2) and those with only HIF- $2 \alpha(\mathrm{H} 2)$ (Gordan et al, 2008). HIF- $1 \alpha$ and HIF- $2 \alpha$ have opposing effects on c-Myc, where HIF- $1 \alpha$ antagonises its activity and HIF- $2 \alpha$ increases it. HIF- $1 \alpha$ inhibits c-Myc activity by promoting its degradation via the proteasome and by binding to and activating Mxi-1, which represses c-Myc transcriptional activity (Zhang et al, 2007a). In contrast, $\mathrm{H} 2$ tumours are associated with high c-Myc activity and increased cellular proliferation compared with $\mathrm{H} 1 \mathrm{H} 2$ tumours (Gordan et al, 2008). As expected, the $\mathrm{H} 2786-\mathrm{O}$ cell line exhibited higher basal c-Myc levels than the $\mathrm{VHL}^{+/+}$Caki-1 cell line in this study. However, c-Myc expression was detected in both cell lines, suggesting that PIM kinase inhibition may be an effective therapeutic strategy in both $\mathrm{VHL}^{-I-}$ and $\mathrm{VHL}^{+1+}$ tumours.

Recent studies demonstrate that PIM kinase expression results in chemoresistance to a number of agents with diverse mechanisms of action including cisplatin, taxane-based therapies, and rapamycin (Zemskova et al, 2008; Beharry et al, 2009; Hu et al, 2009; Mumenthaler et al, 2009; Chen et al, 2009a). In addition, it was recently demonstrated that treatment with docetaxel and cytarabine induced significant increases in PIM kinase expression (Zemskova et al, 2008; Kelly et al, 2011). Given this, PIM kinase inhibitors may have broad-spectrum activity across many malignancies and may be able to overcome resistance to multiple 
classes of anticancer agents with diverse mechanisms of action. Sunitinib continues to be utilised in first-line therapy for RCC and its activity has been mainly attributed to inhibition of tumour angiogenesis (Mendel et al, 2003; Abrams et al, 2003a, b). However, several studies have also reported that sunitinib has antiproliferative and pro-apoptotic effects on tumour cells (Seandel et al, 2006; Xin et al, 2009). In our study, we demonstrated that sunitinib induces PIM-1 expression and that inhibition of PIM kinase activity with SGI-1776 significantly enhanced the efficacy of sunitinib in both in vitro and in vivo models of RCC. Interestingly, the SGI-1776/sunitinib combination led to a further reduction in c-Myc levels, which was associated with decreased tumour proliferation. A recent study showed that sunitinib downregulated c-Myc levels in acute myelogenous leukaemia cells, which was associated with monocytic differentiation (Nishioka et al, 2009). While we did not observe a strong effect of sunitinib on c-Myc levels in RCC cells, sunitinib was able to augment the ability of SGI-1776 to reduce c-Myc expression. In addition to c-Myc, PIM kinases have also been shown to phosphorylate the BH3-only protein Bad at Ser112, which inhibits its pro-apoptotic activity (Yan et al, 2003; Aho et al, 2004; Li et al, 2006). Recent studies in chronic lymphocytic leukaemia and prostate cancer are in agreement with our findings and demonstrate that SGI-1776 induces apoptosis (Mumenthaler et al, 2009; Chen et al, 2009b).

The combination of SGI-1776 and sunitinib dramatically reduced tumour burden in two RCC xenograft models compared with single-agent therapy and was very well tolerated. Sunitinib produced a more potent reduction of tumour burden in the 786-O cell line, which may be due to its $\mathrm{VHL}^{-1-}$ status. However, the SGI$1776 /$ sunitinib combination was equally effective in both $\mathrm{VHL}^{-1-}$

\section{REFERENCES}

Abrams TJ, Lee LB, Murray LJ, Pryer NK, Cherrington JM (2003a) SU11248 inhibits KIT and platelet-derived growth factor receptor beta in preclinical models of human small cell lung cancer. Mol Cancer Ther 2(5): $471-478$

Abrams TJ, Murray LJ, Pesenti E, Holway VW, Colombo T, Lee LB, Cherrington JM, Pryer NK (2003b) Preclinical evaluation of the tyrosine kinase inhibitor SU11248 as a single agent and in combination with 'standard of care' therapeutic agents for the treatment of breast cancer. Mol Cancer Ther 2(10): 1011-1021

Adam M, Pogacic V, Bendit M, Chappuis R, Nawijn MC, Duyster J, Fox CJ, Thompson CB, Cools J, Schwaller J (2006) Targeting PIM kinases impairs survival of hematopoietic cells transformed by kinase inhibitor-sensitive and kinase inhibitor-resistant forms of Fms-like tyrosine kinase 3 and BCR/ABL. Cancer Res 66(7): $3828-3835$

Aho TL, Sandholm J, Peltola KJ, Mankonen HP, Lilly M, Koskinen PJ (2004) Pim-1 kinase promotes inactivation of the pro-apoptotic Bad protein by phosphorylating it on the Ser112 gatekeeper site. FEBS Lett 571(1-3): $43-49$

Amaravadi R, Thompson CB (2005) The survival kinases Akt and Pim as potential pharmacological targets. J Clin Invest 115(10): $2618-2624$

Beharry Z, Zemskova M, Mahajan S, Zhang F, Ma J, Xia Z, Lilly M, Smith CD, Kraft AS (2009) Novel benzylidene-thiazolidine-2,4-diones inhibit Pim protein kinase activity and induce cell cycle arrest in leukemia and prostate cancer cells. Mol Cancer Ther 8(6): 1473-1483

Beier UH, Weise JB, Laudien M, Sauerwein H, Gorogh T (2007) Overexpression of Pim-1 in head and neck squamous cell carcinomas. Int J Oncol 30(6): 1381 - 1387

Carew JS, Medina EC, Esquivel II JA, Mahalingam D, Swords R, Kelly K, Zhang H, Huang P, Mita AC, Mita MM, Giles FJ, Nawrocki ST (2009) Autophagy inhibition enhances vorinostat-induced apoptosis via ubiquitinated protein accumulation. J Cell Mol Med 14(10): $2448-2459$

Chen J, Kobayashi M, Darmanin S, Qiao Y, Gully C, Zhao R, Yeung SC, Lee MH (2009a) Pim-1 plays a pivotal role in hypoxia-induced chemoresistance. Oncogene 28(28): 2581-2592 and $\mathrm{VHL}^{+/+}$xenograft models. Consistent with our in vitro data, analysis of the tumours revealed a decrease in c-Myc levels, which was associated with reduced tumour cell proliferation.

Our results suggest that targeting PIM kinase is a promising new strategy for the treatment of RCC. Its ability to reduce c-Myc activity may have important clinical implications since c-Myc overexpression is estimated to occur in $70 \%$ of human tumours. In addition, PIM kinase inhibition strongly enhances the activity of standard of care agents, such as sunitinib in the current study and platinum- and taxane-based therapies as reported by other investigators ( $\mathrm{Hu}$ et al, 2009; Mumenthaler et al, 2009). Collectively, our data establish PIM kinase as a novel therapeutic target in RCC and provide the foundation for clinical investigation of PIM kinase inhibitors in combination with sunitinib.

\section{ACKNOWLEDGEMENTS}

This work was supported by Congressionally Directed Medical Research Programs (CDMRP) Grant \#W81XWH-07-2-0025, funds provided by The Institute for Drug Development, CTRC at UTHSCSA, and the National Cancer Institute P30 Cancer Center Support Grant \#CA054174.

\section{Conflict of interest}

Dr D Bearss, Dr G Choy, and Dr P Taverna are employees of SuperGen Inc.
Chen JL, Limnander A, Rothman PB (2008) Pim-1 and Pim-2 kinases are required for efficient pre-B-cell transformation by $\mathrm{v}$-Abl oncogene. Blood 111(3): $1677-1685$

Chen LS, Redkar S, Bearss D, Wierda WG, Gandhi V (2009b) Pim kinase inhibitor, SGI-1776, induces apoptosis in chronic lymphocytic leukemia cells. Blood 114(19): 4150-4157

Cibull TL, Jones TD, Li L, Eble JN, Ann Baldridge L, Malott SR, Luo Y, Cheng L (2006) Overexpression of Pim-1 during progression of prostatic adenocarcinoma. J Clin Pathol 59(3): 285-288

Eichmann A, Yuan L, Breant C, Alitalo K, Koskinen PJ (2000) Developmental expression of pim kinases suggests functions also outside of the hematopoietic system. Oncogene 19(9): 1215-1224

Fox CJ, Hammerman PS, Cinalli RM, Master SR, Chodosh LA, Thompson CB (2003) The serine/threonine kinase Pim-2 is a transcriptionally regulated apoptotic inhibitor. Genes Dev 17(15): $1841-1854$

Gordan JD, Bertout JA, Hu CJ, Diehl JA, Simon MC (2007a) HIF-2alpha promotes hypoxic cell proliferation by enhancing c-myc transcriptional activity. Cancer Cell 11(4): 335-347

Gordan JD, Lal P, Dondeti VR, Letrero R, Parekh KN, Oquendo CE, Greenberg RA, Flaherty KT, Rathmell WK, Keith B, Simon MC, Nathanson KL (2008) HIF-alpha effects on c-Myc distinguish two subtypes of sporadic VHL-deficient clear cell renal carcinoma. Cancer Cell 14(6): $435-446$

Gordan JD, Thompson CB, Simon MC (2007b) HIF and c-Myc: sibling rivals for control of cancer cell metabolism and proliferation. Cancer Cell 12(2): $108-113$

Heng DY, Bukowski RM (2008) Anti-angiogenic targets in the treatment of advanced renal cell carcinoma. Curr Cancer Drug Targets 8(8): $676-682$

Hogan C, Hutchison C, Marcar L, Milne D, Saville M, Goodlad J, Kernohan N, Meek D (2008) Elevated levels of oncogenic protein kinase Pim-1 induce the p53 pathway in cultured cells and correlate with increased Mdm2 in mantle cell lymphoma. J Biol Chem 283(26): $18012-18023$

Hu XF, Li J, Vandervalk S, Wang Z, Magnuson NS, Xing PX (2009) PIM-1specific $\mathrm{mAb}$ suppresses human and mouse tumor growth by decreasing 
PIM-1 levels, reducing Akt phosphorylation, and activating apoptosis. J Clin Invest 119(2): $362-375$

Iliopoulos O, Levy AP, Jiang C, Kaelin Jr WG, Goldberg MA (1996) Negative regulation of hypoxia-inducible genes by the von Hippel-Lindau protein. Proc Natl Acad Sci USA 93(20): 10595-10599

Kaelin Jr WG (2007) The von Hippel-Lindau tumor suppressor protein and clear cell renal carcinoma. Clin Cancer Res 13(2 Pt 2): 680s-684s

Kaelin Jr WG (2008) Kidney cancer: now available in a new flavor. Cancer Cell 14(6): $423-424$

Kelly KR, Espitia CM, Taverna P, Choy G, Padmanabhan S, Nawrocki ST, Giles FJ, Carew JS (2011) Targeting PIM kinase activity significantly augments the efficacy of cytarabine. Br J Haematol; e-pub ahead of print 21 June 2011

Li YY, Popivanova BK, Nagai Y, Ishikura H, Fujii C, Mukaida N (2006) Pim-3, a proto-oncogene with serine/threonine kinase activity, is aberrantly expressed in human pancreatic cancer and phosphorylates bad to block bad-mediated apoptosis in human pancreatic cancer cell lines. Cancer Res 66(13): 6741-6747

Mahalingam D, Medina EC, Esquivel II JA, Espitia CM, Smith S, Oberheu K, Swords R, Kelly KR, Mita MM, Mita AC, Carew JS, Giles FJ, Nawrocki ST (2010) Vorinostat enhances the activity of temsirolimus in renal cell carcinoma through suppression of survivin levels. Clin Cancer Res 16(1): $141-153$

Mendel DB, Laird AD, Xin X, Louie SG, Christensen JG, Li G, Schreck RE, Abrams TJ, Ngai TJ, Lee LB, Murray LJ, Carver J, Chan E, Moss KG, Haznedar JO, Sukbuntherng J, Blake RA, Sun L, Tang C, Miller T, Shirazian S, McMahon G, Cherrington JM (2003) In vivo antitumor activity of SU11248, a novel tyrosine kinase inhibitor targeting vascular endothelial growth factor and platelet-derived growth factor receptors: determination of a pharmacokinetic/pharmacodynamic relationship. Clin Cancer Res 9(1): $327-337$

Mochizuki T, Kitanaka C, Noguchi K, Muramatsu T, Asai A, Kuchino Y (1999) Physical and functional interactions between Pim-1 kinase and Cdc25A phosphatase. Implications for the Pim-1-mediated activation of the c-Myc signaling pathway. J Biol Chem 274(26): 18659-18666

Morishita D, Katayama R, Sekimizu K, Tsuruo T, Fujita N (2008) Pim kinases promote cell cycle progression by phosphorylating and downregulating p27Kip1 at the transcriptional and posttranscriptional levels. Cancer Res 68(13): 5076-5085

Moroy T, Verbeek S, Ma A, Achacoso P, Berns A, Alt F (1991) E mu N- and $\mathrm{E}$ mu L-myc cooperate with E mu pim-1 to generate lymphoid tumors at high frequency in double-transgenic mice. Oncogene 6(11): $1941-1948$

Mumenthaler SM, Ng PY, Hodge A, Bearss D, Berk G, Kanekal S, Redkar S, Taverna P, Agus DB, Jain A (2009) Pharmacologic inhibition of Pim kinases alters prostate cancer cell growth and resensitizes chemoresistant cells to taxanes. Mol Cancer Ther 8(10): 2882-2893

Nawrocki ST, Carew JS, Maclean KH, Courage JF, Huang P, Houghton JA, Cleveland JL, Giles FJ, McConkey DJ (2008) Myc regulates aggresome formation, the induction of Noxa, and apoptosis in response to the combination of bortezomib and SAHA. Blood 112(7): 2917-2926

Nilsson JA, Cleveland JL (2003) Myc pathways provoking cell suicide and cancer. Oncogene 22(56): 9007-9021

Nishioka C, Ikezoe T, Yang J, Yokoyama A (2009) Sunitinib, an orally available receptor tyrosine kinase inhibitor, induces monocytic differentiation of acute myelogenous leukemia cells that is enhanced by 1,25-dihydroxyvitamin $\mathrm{D}(3)$. Leukemia 23(11): $2171-2173$
Ohh M, Park CW, Ivan M, Hoffman MA, Kim TY, Huang LE, Pavletich N, Chau V, Kaelin WG (2000) Ubiquitination of hypoxia-inducible factor requires direct binding to the beta-domain of the von Hippel-Lindau protein. Nat Cell Biol 2(7): $423-427$

Pelengaris S, Khan M, Evan G (2002) c-MYC: more than just a matter of life and death. Nat Rev Cancer 2(10): 764-776

Pfaffl MW (2001) A new mathematical model for relative quantification in real-time RT-PCR. Nucleic Acids Res 29(9): e45

Popivanova BK, Li YY, Zheng H, Omura K, Fujii C, Tsuneyama K, Mukaida N (2007) Proto-oncogene, Pim-3 with serine/threonine kinase activity, is aberrantly expressed in human colon cancer cells and can prevent Bad-mediated apoptosis. Cancer Sci 98(3): 321-328

Seandel M, Shia J, Linkov I, Maki RG, Antonescu CR, Dupont J (2006) The activity of sunitinib against gastrointestinal stromal tumor seems to be distinct from its antiangiogenic effects. Clin Cancer Res 12(20 Pt 1): $6203-6204$

Sosman JA, Puzanov I, Atkins MB (2007) Opportunities and obstacles to combination targeted therapy in renal cell cancer. Clin Cancer Res 13(2 Pt 2): 764s-769s

Tang SW, Chang WH, Su YC, Chen YC, Lai YH, Wu PT, Hsu CI, Lin WC, Lai MK, Lin JY (2009) MYC pathway is activated in clear cell renal cell carcinoma and essential for proliferation of clear cell renal cell carcinoma cells. Cancer Lett 273(1): 35-43

Turner KJ, Moore JW, Jones A, Taylor CF, Cuthbert-Heavens D, Han C, Leek RD, Gatter KC, Maxwell PH, Ratcliffe PJ, Cranston D, Harris AL (2002) Expression of hypoxia-inducible factors in human renal cancer: relationship to angiogenesis and to the von Hippel-Lindau gene mutation. Cancer Res 62(10): 2957-2961

Workman P, Aboagye EO, Balkwill F, Balmain A, Bruder G, Chaplin DJ, Double JA, Everitt J, Farningham DA, Glennie MJ, Kelland LR, Robinson V, Stratford IJ, Tozer GM, Watson S, Wedge SR, Eccles SA (2010) Guidelines for the welfare and use of animals in cancer research. $\mathrm{Br} J$ Cancer 102(11): $1555-1577$

Xin H, Zhang C, Herrmann A, Du Y, Figlin R, Yu H (2009) Sunitinib inhibition of Stat3 induces renal cell carcinoma tumor cell apoptosis and reduces immunosuppressive cells. Cancer Res 69(6): 2506-2513

Yan B, Zemskova M, Holder S, Chin V, Kraft A, Koskinen PJ, Lilly M (2003) The PIM-2 kinase phosphorylates BAD on serine 112 and reverses BAD-induced cell death. J Biol Chem 278(46): 45358-45367

Zemskova M, Sahakian E, Bashkirova S, Lilly M (2008) The PIM1 kinase is a critical component of a survival pathway activated by docetaxel and promotes survival of docetaxel-treated prostate cancer cells. J Biol Chem 283(30): $20635-20644$

Zhang H, Gao P, Fukuda R, Kumar G, Krishnamachary B, Zeller KI, Dang CV, Semenza GL (2007a) HIF-1 inhibits mitochondrial biogenesis and cellular respiration in VHL-deficient renal cell carcinoma by repression of C-MYC activity. Cancer Cell 11(5): 407-420

Zhang Y, Wang Z, Li X, Magnuson NS (2008) Pim kinase-dependent inhibition of c-Myc degradation. Oncogene 27(35): 4809-4819

Zhang Y, Wang Z, Magnuson NS (2007b) Pim-1 kinase-dependent phosphorylation of p21Cip1/WAF1 regulates its stability and cellular localization in H1299 cells. Mol Cancer Res 5(9): $909-922$

Zippo A, De Robertis A, Serafini R, Oliviero S (2007) PIM1-dependent phosphorylation of histone $\mathrm{H} 3$ at serine 10 is required for MYCdependent transcriptional activation and oncogenic transformation. Nat Cell Biol 9(8): $932-944$

This work is published under the standard license to publish agreement. After 12 months the work will become freely available and the license terms will switch to a Creative Commons Attribution-NonCommercial-Share Alike 3.0 Unported License. 